\title{
A mechanism of pathogenicity of "Streptococcus milleri group" in pulmonary infection: synergy with an anaerobe
}

\author{
T. SHINZATO and A. SAITO
}

First Department of Internal Medicine, Faculty of Medicine, University of the Ryukyus, 207 Uehara, Nishihara-cho, Okinawa 903-01, Japan

\begin{abstract}
Summary. The relationship between Streptococcus constellatus, one of the species of the "Streptococcus milleri group", and Prevotella intermedia was studied in a model of pneumonia in mice and in vitro to elucidate mechanisms of pathogenicity in " $S$. milleri group"-associated pulmonary infection. Acute pneumonia with or without empyema and lung abscess in mice with mixed infection resulted in $60 \%$ mortality rate, but there was only $10 \%$ mortality and mild pneumonia in each separate infection. Bacterial clearance of organisms, especially $S$. constellatus, in mixed infection was delayed. Enhancement of growth of $S$. constellatus was demonstrated when cultured with $P$. intermedia; growth was also stimulated by a culture filtrate of $P$. intermedia which also inhibited bactericidal activity of human neutrophils. In an examination of infectivity and bacterial clearance of $S$. constellatus with $P$. intermedia culture filtrate in vivo, there was $20 \%$ mortality and delayed clearance of $S$. constellatus, although the infection was not as severe as that produced by the combination of both organisms. These results suggest that $P$. intermedia may act with $S$. constellatus in the production of pulmonary infections by stimulating its growth and suppressing bactericidal activity of the host.
\end{abstract}

\section{Introduction}

"Streptococcus milleri group" describes a group of anaerobic- or micro-aerophilic streptococci including $S$. anginosus, $S$. constellatus and $S$. intermedius. "S. milleri group" organisms are commonly found in the mouth, nasopharynx, gastrointestinal tract and vagina, at a rate of $15-30 \% .^{1}$ They are often associated with various pyogenic infections and involved in mixed infections, especially in combination with anaerobes. ${ }^{2}$ Infection with these organisms may arise by local invasion from their usual habitats. ${ }^{3}$

Although " $S$. milleri group" organisms have also been isolated from pneumonia, empyema and lung abscess $^{3-6}$ they are often unrecognised as pathogens in pulmonary infections because their pathogenicity and pathogenic mechanisms have not been fully determined.'

This study investigated these mechanisms in a model of pneumonia in mice and by in-vitro studies.

\section{Materials and methods}

The synergy between $S$. constellatus and Prevotella intermedia was studied in the following stages in vivo and in vitro: (i) Infectivity of $S$. constellatus and $P$. intermedia separately and in combination in mice was studied. Experiments were carried out when the results in vivo suggested that $P$. intermedia or its metabolic substances might stimulate the growth of $S$. constellatus and inhibit the defence mechanisms of the host.

(ii) Growth enhancement of $S$. constellatus in broth was investigated with $P$. intermedia and its cell-free culture filtrate.

(iii) Bactericidal activity of human polymorphonuclear leucocytes (PMNLs) was examined to determine the effect of $P$. intermedia culture filtrate on host defence mechanisms.

(iv) Infectivity of $S$. constellatus in combination with the culture filtrate of $P$. intermedia was studied in vivo.

\section{Bacterial strains}

$S$. constellatus RZYK 001 and $P$. intermedia RZST 004 were isolated from broncho-alveolar lavage fluid and purulent sputum obtained by bronchoscopy. Staphylococcus aureus ATCC 25923 was used for the study on the bactericidal activity of PMNLs.

\section{Culture}

S. constellatus was cultured on Trypto-Soy Blood Agar (Kyokuto Pharmaceutical Industrial Co., 
Tokyo, Japan) for $24 \mathrm{~h}$ at $37^{\circ} \mathrm{C}$ in air with $\mathrm{CO}_{2} 5 \%$ and $P$. intermedia was grown on Brucella HK Agar (Kyokuto Pharmaceutical Industrial Co.) supplemented with sheep blood $5 \%$ for $48 \mathrm{~h}$ in an anaerobic chamber in an atmosphere of $\mathrm{N}_{2} 80 \%, \mathrm{H}_{2} 10 \%$ and $\mathrm{CO}_{2} 10 \%$. Vancomycin $2.5 \mu \mathrm{g} / \mathrm{ml}$ was added to Brucella HK agar to select $P$. intermedia from lung homogenate and culture broth. $S$. aureus was grown on Trypticase Soy Agar (Becton Dickinson, Cockeysville, MD, USA) for $18 \mathrm{~h}$ at $37^{\circ} \mathrm{C}$.

\section{Preparation of culture filtrate of $P$. intermedia}

$P$. intermedia was cultured in peptone-yeast-glucose (PYG) broth until it overgrew. The broth was then centrifuged $(15000 \mathrm{rpm}$ for $30 \mathrm{~min})$ and the $\mathrm{pH}$ adjusted to 7.2 with $1.0 \mathrm{M}$ and $0.1 \mathrm{M} \mathrm{NaOH}$. The total volume change with $\mathrm{pH}$ titration was small. The broth was sterilised by passage through a $0 \cdot 22-\mu \mathrm{m}$ filter (Millipore). A $P$. intermedia culture filtrate from Schaedler Broth (Hoffmann-La Roche, Germany) was prepared by the same method for the study of growth enhancement of $S$. constellatus.

\section{Infectivity testing}

Male BALB/c mice (20-22 g), raised in conventional conditions were used. $S$. constellatus and $P$. intermedia were suspended in PYG broth ( $\mathrm{pH} 7 \cdot 2)$ at concentrations of $10^{9}$ and $10^{10} \mathrm{cfu} / \mathrm{ml}$, respectively. In the studies examining the effects of $P$. intermedia culture filtrate, $S$. constellatus was suspended in the culture filtrate and the concentration was adjusted to $10^{9} \mathrm{cfu} / \mathrm{ml}$. Mice were anaesthetised with pentobarbital and $0.07 \mathrm{ml}$ of the bacterial suspension was inoculated via a 22 gauge catheter inserted into the trachea; control mice were similarly challenged with an equal volume of PYG broth.

Groups of 10 mice, inoculated with separate species or a combination, were observed over 14 days to determine the mortality rate.

Four mice from each initial group of 20, including a control group, were killed by cutting the axillary arteries at $0,3,7,11$ and 14 days after bacterial challenge and examined histologically. Formalin $10 \%$ was infused through the trachea and the lungs were removed surgically and fixed in formalin $10 \%$ for $24 \mathrm{~h}$. They were then embedded in paraffin, and sections were cut and stained with haematoxylin and eosin.

Three or four mice from groups of 30 were killed by cervical dislocation at $0,6,12,24,36,48$ and $60 \mathrm{~h}$ after bacterial challenge for quantitative lung culture. The lungs with attached bronchi were removed aseptically and homogenised in $1 \mathrm{ml}$ of PYG broth inside an anaerobic chamber. Serial 10 -fold dilutions of the homogenates were performed with phosphatebuffered saline (PBS, pH 7.4) containing dithiothreitol
$0.05 \%$, and cultured on soybean-casein digest agar and Brucella $\mathrm{HK}$ agar with sheep blood $5 \%$.

\section{Assay of growth enhancement effect for S. constellatus}

Studies on the growth of $S$. constellatus and $P$. intermedia were performed in Schaedler broth containing vitamin $\mathrm{K}_{1}$. The mixed and single cultures of $S$. constellatus and $P$. intermedia were incubated in anaerobic conditions. Growth enhancement of $S$. constellatus was investigated with $P$. intermedia culture filtrate adjusted to $\mathrm{pH} 7 \cdot 2$. Counts of bacterial colonies were performed every $3 \mathrm{~h}$ by inoculating serial dilutions on agar plates.

\section{Measurement of bactericidal activity of PMNLs}

PMNLs were separated from heparinised peripheral blood of a healthy adult by centrifugation with MonoPoly Resolving Medium (Flow Laboratories, Inc., Tokyo, Japan). The purity of PMNLs was $>95 \%$ and the proportion of viable cells was $>95 \%$. They were then suspended in Hanks's Balanced Salts Solution, pH 7.4 (HBSS; Gibco Laboratories, Grand Island, NY, USA). A $1-\mathrm{ml}$ suspension containing PMNLs $\left(5 \times 10^{6}\right.$ cells $), S$. aureus suspension $\left(1 \times 10^{6} \mathrm{cfu}\right)$, normal human serum (15\%), HBSS, and either $P$. intermedia culture filtrate, sterile PYG broth or PBS was made in Falcon 2063 polypropylene tubes and rotated slowly at $37^{\circ} \mathrm{C}$ for $120 \mathrm{~min}$. After incubation, a sample of the mixture was added to cold distilled water to disrupt the PMNLs, and viable bacterial counts were performed by plating serial 10 -fold dilutions on soybean-casein digest agar. Tubes without PMNLs were treated similarly as controls. Results were expressed as a killing index. ${ }^{8}$ Killing index $(\%)=[($ number of viable bacteria without PMNLs) - (number of viable bacteria with PMNLs)]/number of viable bacteria without PMNLs $\times 100$.

\section{Statistical analysis}

The data were expressed as means and SDs. Statistical comparison of survival rates was performed by Wilcoxon's test and in other investigations by Student's $t$ test.

\section{Results}

\section{Pneumonia induced by $S$. constellatus and $P$. intermedia}

Histological findings and mortality are shown in table I. $S$. constellatus and $P$. intermedia caused pneumonia when inoculated separately; histopathological examination showed acute bronchopneumonia on days 1 and 3 , and the number of neutrophils after 3 days fell considerably compared to day 1 . The pneumonia improved by 7 days, no abscesses developed 
Table I. Infectivity of $S$. constellatus and $P$. intermedia separately and in combination when inoculated into lungs of mice

\begin{tabular}{lccc}
\hline \multirow{2}{*}{ Inoculum* } & \multicolumn{2}{c}{ Histological findings } & Mortality $\dagger$ \\
\cline { 2 - 3 } S. constellatus & $\begin{array}{c}\text { Mild, } \\
\text { improved by 7 days }\end{array}$ & None & $10 \%$ \\
P. intermedia & $\begin{array}{c}\text { Mild, } \\
\text { improved by 7 days }\end{array}$ & None & $10 \%$ \\
$\begin{array}{l}\text { S. constellatus } \\
\text { Severe, }\end{array}$ & $\begin{array}{c}60 \% \\
\text { P. intermedia } \text { continued for 14 days } \\
\text { (complicated with } \\
\text { empyema in one case) }\end{array}$ & $60 \% \ddagger$ \\
\hline
\end{tabular}

*Each organism was suspended in PYG broth and inoculated into mice as described in Materials and methods.

$\dagger \mathrm{n}=10$ in each group.

$\ddagger \mathrm{p}<0.05$ compared with single infection by $S$. constellatus or $P$. intermedia.

and only $10 \%$ of mice with either of the single infections died; deaths occurred on the second day. Examination of the lungs from the mice that died demonstrated severe pneumonia. The combination of $S$. constellatus and $P$. intermedia induced acute pneumonia which continued even after 7 days. Alveoli were filled with neutrophils, and alveolar haemorrhage with pulmonary oedema was prominent on the third day. Aggregates of neutrophils remained and the structure of alveoli was severely damaged by the seventh day. Abscesses developed within 8-14 days. S. constellatus was the organism most commonly isolated. Sixty percent of mice died of acute pneumonia within $2-5$ days $(p<0.05$ compared with infection by separate organisms). No significant findings were demonstrated in control mice.

Infection either by $S$. constellatus or $P$. intermedia was cleared from the lungs by $60 \mathrm{~h}$ whereas viable bacteria remained in mice inoculated with mixed organisms $60 \mathrm{~h}$ after inoculation; the number of $S$. constellatus remained at approximately the same level (fig. 1).

\section{Growth stimulation of $S$. constellatus with $P$. intermedia or culture filtrate of $P$. intermedia}

Growth of $S$. constellatus in combination with $P$. intermedia was eight times greater than that of $S$. constellatus alone at maximal growth (fig. 2). The number of $P$. intermedia in mixed culture gradually increased with time. Growth of $S$. constellatus in the mixed culture was stimulated as the number of $P$. intermedia increased. More rapid growth and larger numbers of $S$. constellatus were observed in broth

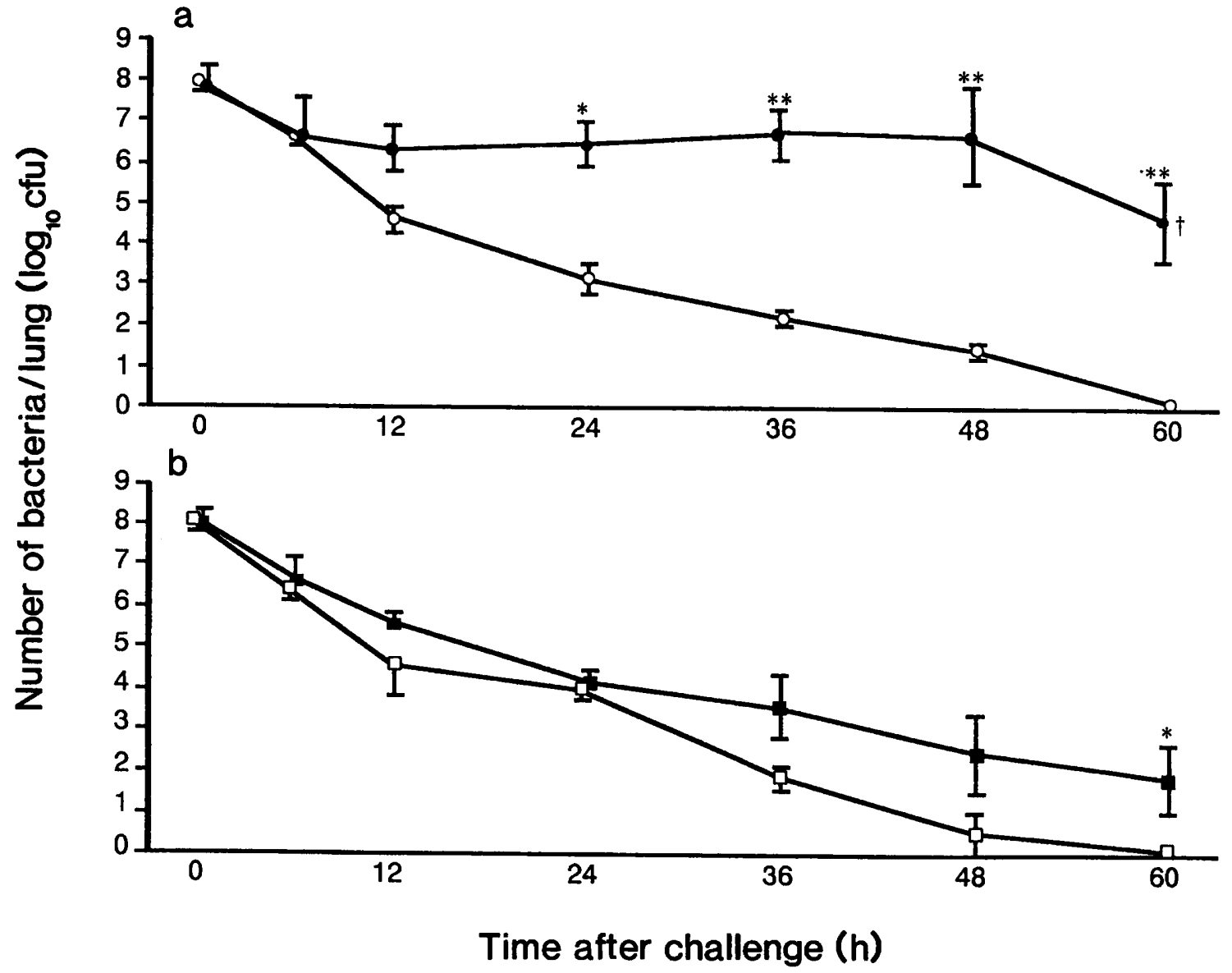

Fig. 1. Clearance of $S$. constellatus (a: $\bigcirc$ and $O$ ) and $P$. intermedia (b: $\square$ and $\square$ ) from lungs in single ( $\bigcirc$ and $\square$ ) and mixed ( $\bigcirc$ and $\square$ ) infection. Values are expressed as means and SD for three or four mice/group; ${ }^{*} \mathrm{p}<0.05$ and ${ }^{* *} \mathrm{p}<0.005$ compared to the number of bacteria in single infection. 


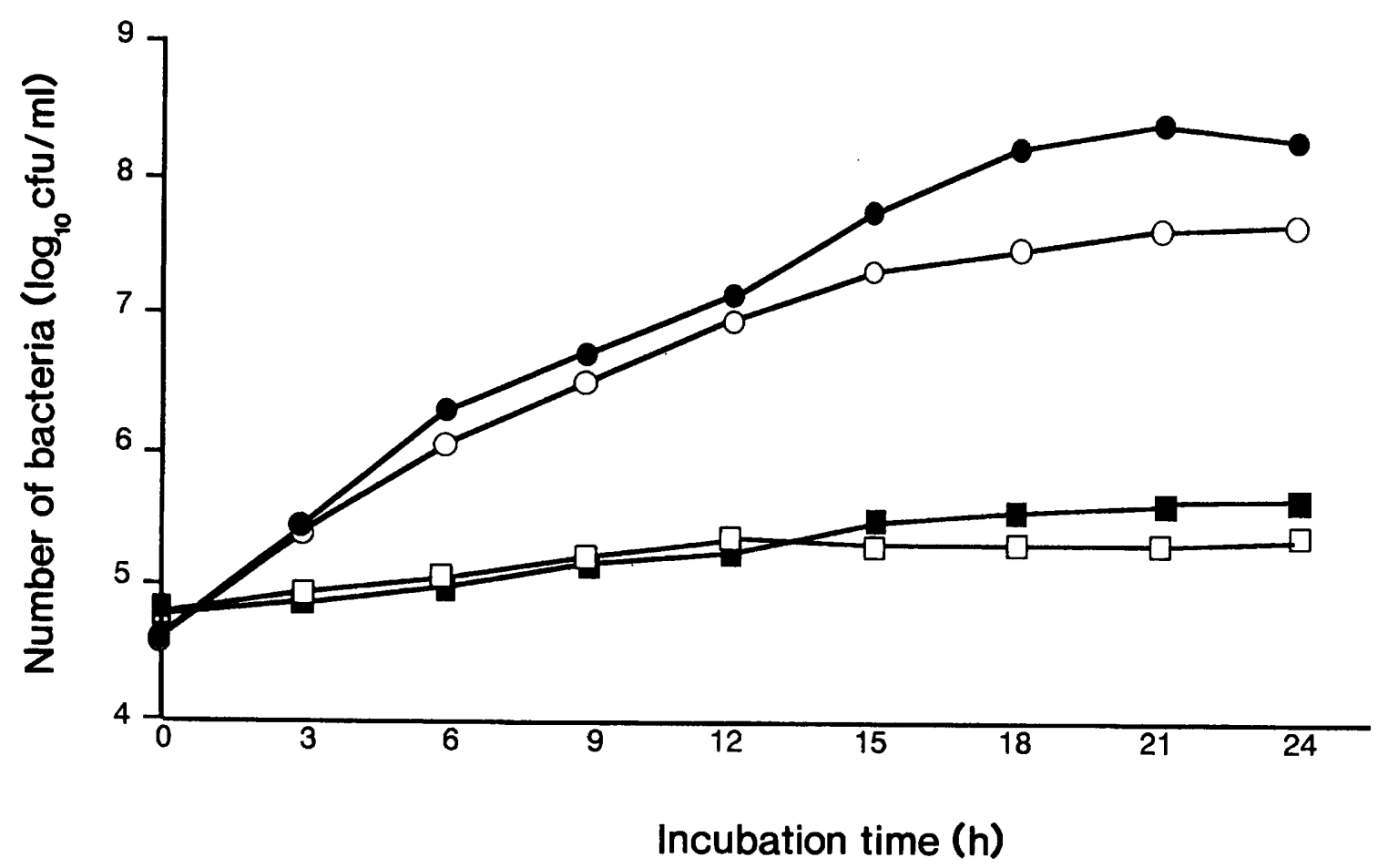

Fig. 2. Growth of $S$. constellatus and $P$. intermedia during mixed ( and $\square$, respectively) and individual ( $\bigcirc$ and $\square$, respectively) cultures.

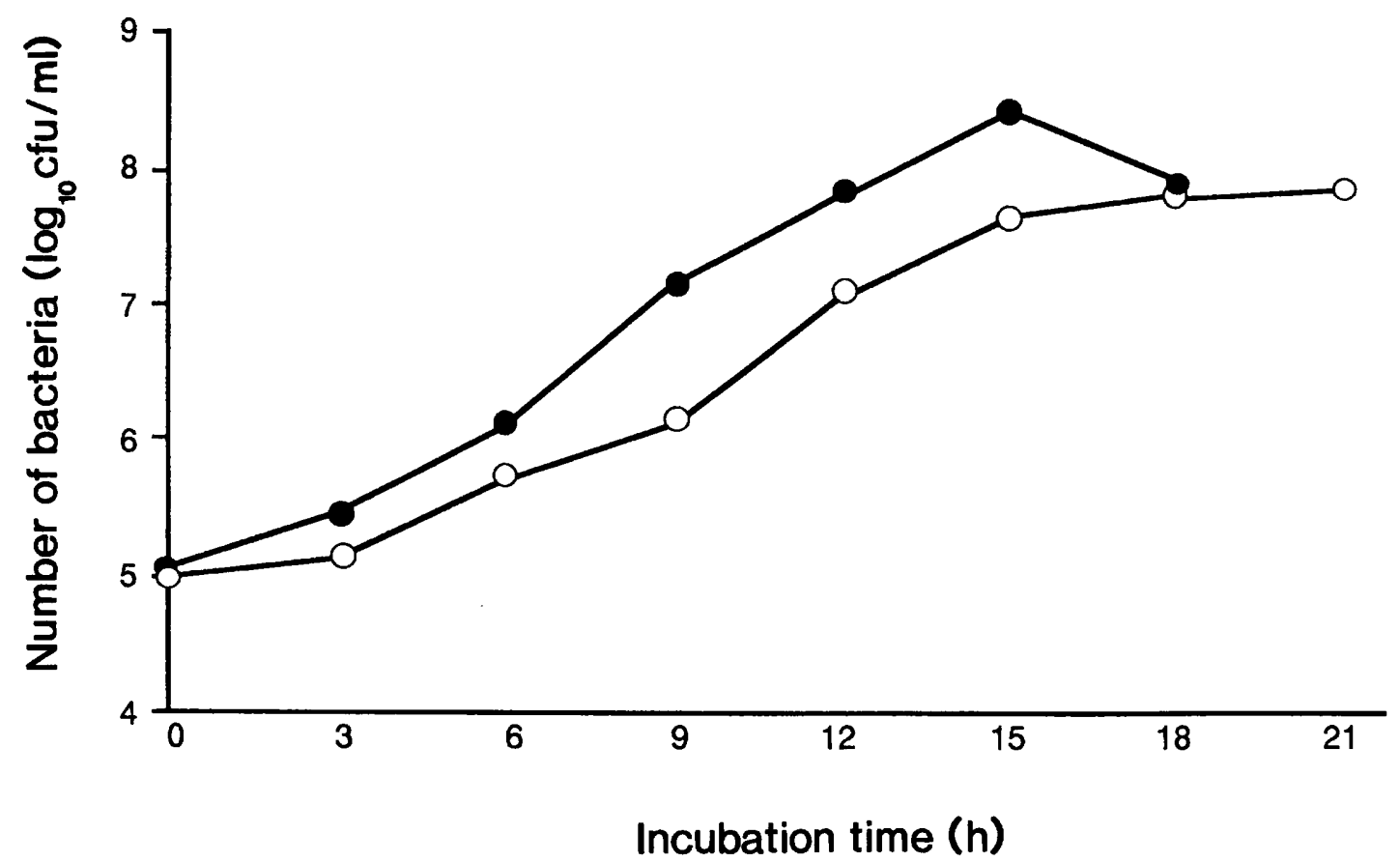

Fig. 3. Growth of $S$. constellatus in broth with $(\bullet)$ and without $(O) P$. intermedia culture filtrate.

containing $P$. intermedia culture filtrate than when cultured in broth without the filtrate (fig. 3).

Effect of culture filtrate of $P$. intermedia on bactericidal activity of human PMNLs

Viable counts of $S$. aureus after incubation for 120 min with PMNLs are shown in table II. The killing index of PMNLs incubated with PYG broth and PBS was $59 \%$ in both cases, but only $31 \%$ with
$P$. intermedia culture filtrate; this represented a significant reduction $(p<0.01)$ in their bactericidal activity.

Infectivity of S. constellatus with culture filtrate of $P$. intermedia

Twenty percent of mice died within 4 days after inoculation with $S$. constellatus and $P$. intermedia culture filtrate, whereas there were no deaths after inoculation with $S$. constellatus alone. There were 
Table II. Effect of $P$. intermedia culture filtrate on the killing of $S$. aureus by human PMNLs

\begin{tabular}{lc}
\hline PMNLs incubated with* & Killing index $(\%) \dagger$ \\
\hline PBS & $58.9(9 \cdot 9)$ \\
PYG broth & $59 \cdot 1(9 \cdot 0)$ \\
$P$. intermedia culture filtrate & $30 \cdot 9(6 \cdot 2) \ddagger$ \\
\hline
\end{tabular}

${ }^{*}$ Human PMNLs were incubated with each broth at $37^{\circ} \mathrm{C}$ for $120 \mathrm{~min}$.

$\dagger$ Defined in Materials and methods. Data are the mean and (SD) of three experiments performed in duplicate.

$\ddagger \mathrm{p}<0.01$ compared with cells incubated with PBS and PYG broth.

Table III. Changes in number of $S$. constellatus in the lungs of mice after inoculation

\begin{tabular}{|c|c|c|c|}
\hline \multirow{2}{*}{ Inoculum } & \multicolumn{3}{|c|}{ Number of viable $S$. constellatus ${ }^{*}$ at } \\
\hline & $0 \mathrm{~h}$ & $24 \mathrm{~h}$ & $48 \mathrm{~h}$ \\
\hline S. constellatus & $8 \cdot 2(0 \cdot)$ & $3.6(0.7)$ & $1 \cdot 6(0 \cdot 3)$ \\
\hline $\begin{array}{l}\text { S. constellatus } \\
\text { with } P \text {. intermedia } \\
\text { culture filtrate }\end{array}$ & $8 \cdot 1(0 \cdot 3)$ & $4 \cdot 7(0 \cdot 1) \dagger$ & $3 \cdot 7(0 \cdot 8) \S$ \\
\hline $\begin{array}{l}S . \text { constellatus } \\
+P . \text { intermedia }\end{array}$ & $7.9(0.5)$ & $6 \cdot 3(0 \cdot 7) \ddagger$ & $6 \cdot 7(1 \cdot 7) \|$ \\
\hline
\end{tabular}

*Data expressed as $\log _{10}$ cfu (SD) of organisms, four mice/group. $t \mathrm{p}<0.05$ compared to $S$. constellatus.

$\ddagger \mathrm{p}<0.05$ compared to $S$. constellatus and $S$. constellatus with $P$. intermedia culture filtrate.

$\S \mathrm{p}<0.01$ compared to $S$. constellatus.

$\| \mathrm{p}<0.005$ compared to $S$. constellatus and $\mathrm{p}<0.01$ compared to $S$. constellatus with $P$. intermedia culture filtrate.

significant numbers of viable bacteria in mice inoculated with $S$. constellatus and culture filtrate after $48 \mathrm{~h}$, but fewer than in mice inoculated with $S$. constellatus and viable $P$. intermedia (table III).

\section{Discussion}

The "S. milleri group" are associated with pyogenic infections, bacteraemia and endocarditis, and are also relatively common pathogens in pulmonary infections. Despite this clinical significance there have been few reports on the pathogenic mechanisms of the "S. milleri group" in pulmonary infections.

Anaerobes are known to inhabit areas of the human body similar to those where " $S$. milleri group" organisms are found, and anaerobes of oral origin, particularly of the genera Peptostreptococcus, Prevotella or Fusobacterium, mixed with micro-aerophilic streptococci, have often been isolated from pulmonary infections. ${ }^{2,9,10}$ This suggests the possibility of synergy in the production of " $S$. milleri group" virulence.

This study demonstrated that whereas $S$. constellatus or $P$. intermedia alone induced pneumonia, $S$. constellatus in combination with $P$. intermedia produced a more severe pneumonia and higher mortality. Moreover, miceinfected with the combination of organisms also developed lung abscesses or empyema. These experiments demonstrate synergy in mixed infection with $S$. constellatus and $P$. intermedia.

The following mechanisms of synergy between certain aerobes and anaerobes have been suggested: ${ }^{11}$ production of various growth factors by the microbes; the ability of anaerobes by their metabolic products or capsules to inhibit phagocytosis of aerobes by leucocytes; alteration of the local environment including reduction of the oxygen tension and lowering of the redox potential; and the production of substances toxic to the host.

There are several examples of growth enhancement effects in experimental models. In Meleney's gangrene models, ${ }^{12}$ a heat-labile growth factor produced by $S$. aureus stimulated growth of steptococci including $S$. intermedius, one of the species of the "S. milleri group".

Several studies have examined the mechanisms by which anaerobes affect host defences. Jones and Gemmell ${ }^{13}$ showed that Bacteroides melaninogenicus (now Prevotella melaninogenica) supernate impaired phagocytosis by PMNLs. Similar results have been obtained in other studies with Prevotella, Porphyromonas and Fusobacterium species. ${ }^{14,15}$ Okuda and Takozoe $^{16}$ demonstrated that capsular material inhibited phagocytosis and phagocytic killing of other micro-organisms by leucocytes and Brook and Walker ${ }^{17}$ suggested that the presence of a polysaccharide capsule might be a necessary virulence factor in suppurative infections. Most of the $S$. constellatus and $P$. intermedia cells used in this study were capsulated.

In our in-vitro study, $S$. constellatus multiplied at a greater rate in the culture mixed with. either $P$. intermedia or the cell-free culture filtrate than when cultured alone in the broth. Furthermore, $P$. intermedia culture filtrate inhibited bactericidal activity of human PMNLs, indicating that $P$. intermedia or some of its metabolic substances might help $S$. constellatus survive and multiply. $P$. intermedia and cell-free culture filtrate delayed pulmonary clearance of $S$. constellatus when injected into mice.

The combination of $S$. constellatus with $P$. intermedia culture filtrate was not as virulent as that of $S$. constellatus with viable $P$. intermedia. The " $S$. milleri group" produces extracellular enzymes such as hyaluronidase, DNAase, gelatinase and collagenase $\mathrm{s}^{18-20}$ and releases an immunosuppressive substance. ${ }^{21}$ Some anaerobes exhibit similar extracellular enzyme-releasing activity; a strain of $P$. intermedia examined by Rudek $^{22}$ produced several enzymes. Although the virulent mechanisms of " $S$. milleri group" organisms and anaerobes have not been fully determined, these bacteria may co-operate to damage pulmonary tissue, invade and spread by production of various extracellular enzymes.

Auwera ${ }^{2}$ reported that " $S$. milleri group" organisms were more often isolated together with anaerobes from clinical specimens, but in the study by Kambal, ${ }^{7} 61 \%$ of isolates were obtained in pure culture. The use of 
antibiotics such as metronidazole which suppresses anaerobes but does not affect the "S. milleri group" may also influence their pathogenic potential. ${ }^{23}$

Clearance of $S$. constellatus from mice inoculated with mixed organisms was delayed compared with that of $P$. intermedia. This is analogous to the finding in Lewis's subcutaneous abscess model ${ }^{24}$ that only $S$. milleri could be recovered from abscesses in some animals despite having been inoculated in combination with Peptostreptococcus spp.

In this study a combination of only two organisms was investigated and, although it may not accurately

\section{References}

1. Poole PM, Wilson G. Occurrence and cultural features of Streptococcus milleri in various body sites. J Clin Pathol $1979 ; 32: 764-768$.

2. Van der Auwera P. Clinical significance of Streptococcus milleri. Eur J Clin Microbiol 1985; 4: 386-390.

3. Miller SD, Mauff AC, Koornhof HJ. Streptococcus milleri causing infection in man. $S$ Afr Med $J$ 1983; 63: 684 686.

4. Waitkins SA, Ratcliffe JG, Roberts C. Streptococcus milleri found in pulmonary empyemas and abscesses. J Clin Pathol $1985 ; 38$ : $716-717$.

5. Hocken DB, Dussek JE. Streptococcus milleri as a cause of pleural empyema. Thorax 1985; 40: 626-628.

6. Kohno $\mathrm{S}$, Watanabe $\mathrm{K}$, Hamamoto $\mathrm{A}$ et al. Transthoracic needle aspiration of the lung in respiratory infections. Tohoku J Exp Med 1988; 158: 227-235.

7. Kambal AM. Isolation of Streptococcus milleri from clinical specimens. J Infect 1987; 14: 217-223.

8. Rotstein OD, Pruett TL, Fiegel VD, Nelson RD, Simmons RL. Succinic acid, a metabolic by-product of Bacteroides species, inhibits polymorphonuclear leukocyte function. Infect Immun 1985; 48: 402-408.

9. Bartlett JG. Anaerobic bacterial infections of the lung. Chest 1987; 91 : 901-909.

10. Finegold SM. Anaerobic pulmonary infection. Hosp Pract $1989 ; 15: 103-133$.

11. Rotstein OD, Pruett TL, Simmons RL. Mechanisms of microbial synergy in polymicrobial surgical infections. Rev Infect Dis 1985; 7: 151-170.

12. Mergenhagen SE, Thonard JC, Scherp HW. Studies on synergistic infections. I. Experimental infections with anaerobic streptococci. J Infect Dis 1958; 103: 33-44.

13. Jones GR, Gemmell CG. Impairment by Bacteroides species of opsonisation and phagocytosis of enterobacteria. $\mathrm{J} \mathrm{Med}$ Microbiol 1982; 15: 351-361. reflect a clinical " $S$. milleri group"-associated pulmonary infection from which more than two organisms are sometimes recovered, ${ }^{9,10}$ it provides some information regarding the pathogenicity of " $S$. milleri group" and anaerobes in pulmonary infections.

In conclusion, we suggest that " $S$. milleri group" virulence is enhanced by the presence of the anaerobe $P$. intermedia.

We thank Professor Hokama of the Department of Clinical Laboratory Medicine and Professor Iwanaga of the Department of Bacteriology for their support, and Dr N. Kusano for his excellent instruction.

14. Ingham HR, Sisson PR, Tharagonnet D, Selkon JB, Codd AA. Inhibition of phagocytosis in vitro by obligate anaerobes. Lancet 1977; 2: 1252-1254.

15. Namavar F, Verweij AMJJ, Bal M, van Steenbergen TJM, de Graaff J, McLaren DM. Effect of anaerobic bacteria on killing of Proteus mirabilis by human polymorphonuclear leukocytes. Infect Immun 1983; 40: 930-935.

16. Okuda K, Takozoe I. Antiphagocytic effects of the capsular structure of a pathogenic strain of Bacteroides melaninogenicus. Bull Tokyo Dent Coll 1973; 14: 99-104.

17. Brook I, Walker RI. The role of encapsulation in the pathogenesis of anaerobic gram-positive cocci. Can J Microbiol 1985; 31: 176-180.

18. Unsworth PF. Hyaluronidase production in Streptococcus milleri in relation to infection. J Clin Pathol 1989; 42: 506-510.

19. Steffen EK, Hentges DJ. Hydrolytic enzymes of anaerobic bacteria isolated from human infections. J Clin Microbiol 1981; 14: 153-156.

20. Ruoff KL, Ferraro MJ. Hydrolytic enzymes of "Streptococcus milleri". J Clin Microbiol 1987; 25: 1645-1647.

21. Arala-Chaves MP, Higerd TB, Porto MT et al. Evidence for the synthesis and release of strongly immunosuppressive, noncytotoxic substances by Streptococcus intermedius. $J$ Clin Invest 1979; 64: 871-883.

22. Rudek W, Haque R-U. Extracellular enzymes of the genus Bacteroides. J Clin Microbiol 1976; 4: 458-460.

23. Tresadern JC, Farrand RJ, Irving MH. Streptococcus milleri and surgical sepsis. Ann R Coll Surg Engl 1983; 65: 78-79.

24. Lewis MAO, Macfarlane TW, Mcgowan DA, MacDonald DG. Assessment of the pathogenicity of bacterial species isolated from acute dentoalveolar abscesses. J Med Microbiol 1988; 27 : 109-116. 